\title{
Investigation and Analysis of the Current Situation of VAE Preventive Measures in ICU in Beijing-Tianjin-Hebei Urban Agglomeration of China
} Kang Longfei ${ }^{1,2}$, Okada Shinobu ${ }^{{ }^{\star}}$ and Ogawa Toshiko ${ }^{1}$

${ }^{1}$ Graduate School of Nursing, Chiba University, Japan

${ }^{2}$ The First Hospital of Hebei Medical University, Emergency Department, China

\section{Abstract}

Objective: To understand the implementation of VAE (Ventilator-associated Event) preventive measures and their influencing factors in ICU of tertiary A-level hospitals in the Beijing-Tianjin-Hebei region of China.

Methods: A self-designed web-based questionnaire was used to conduct a cross-sectional survey of 32 ICUs in Beijing, Tianjin, and Hebei to investigate the implementation of ventilator-related event prevention measures, and t-tests and chi-square tests were performed on the collected data.

Results: A total of 32 ICUs responded to the questionnaire. The results showed that the recommended precautions were not standardized. Nearly half of ICUs did not perform oral care with recommended frequency (more than 3 times a day or more), and only eight of all ICUs used toothbrushes. The implementation rate of daily SAT and SBT was low, and only more than half of ICUs chose dexmedetomidine as the primary sedative medication; We found that nurse bed and MV patient ratio were significantly associated with SAT and oral care frequency when the relationship between the characteristics of ICU and the implementation of VAE preventive measures was analyzed.

Conclusions: The questionnaire shows that it is necessary to improve the compliance of daily SAT and SBT and the frequency of oral care and brushing and to place sufficient medical staff to increase the compliance of these VAE precautions.

\section{Introduction}

The incidence of ventilator-associated pneumonia (VAP) has always been an important surveillance indicator for healthcare-associated infections, as up to $28 \%$ of patients receiving mechanical ventilation (MV) will have a clinical course complicated by VAP episode, and the incidence of pneumonia is 21 times higher in patients with tracheal intubation than in those without a manual airway [1-5]. Each country, including China, has developed VAP guidelines and recommended VAP prophylaxis such as spontaneous awakening trial (SAT), spontaneous breathing trial (SBT) and oral care.

Recently, VAP surveillance has been replaced by ventilatorassociated events (VAE) surveillance due to the diagnostic difficulty of VAP. VAE surveillance aims to purposefully identify significant MV associated events and associated complications in patients with MV, including VAP, pulmonary edema, pulmonary embolism, pneumothorax, atelectasis, etc. In the VAE surveillance algorism [6], ventilator-associated conditions (VAC) are first screened and then infection-associated VAC (IVAC) is assessed when VAE indicators meet the IVAC criteria. IVAC is classified as possible or provable pneumonia (PVAP) if the infection is confirmed from the sputum/ BAL examination and/or culture result.

In addition to VAP prophylaxis, the following measures have been shown to be effective in preventing VAE: 1) Management of negative body fluid balance: studies have shown that $30 \%$ to $40 \%$ of VAE develop from the conditions which cause excess body fluid including congestive heart failure, pulmonary edema, and new pleural effusion, etc. [7-10]. Positive fluid balance is identified as an independent risk factor for VAE in a case-control study [11]. 2) Avoidance of excessive sedation: Deep or continuous sedation may prolong MV, and thus increase the risk of VAE. Deep sedation is associated with the risk of complications such as atelectasis, aspiration, and obstruction of the respiratory tract by secretion, all of which increase the risk of developing pneumonia. Benzodiazepines and propofol were associated with an increased VAE risk, but not dexmedetomidine [12]. 3) Low tidal volume ventilation (LTVV): Several studies have shown that low tidal volume MV reduce ARDS, atelectasis, and lung infections in patients without ARDS [13-15]. 4) Maintenance of gastric acid: Anti-ulcerative agents are prophylactically administered in MV patients to prevent stress ulcers. The increased $\mathrm{pH}$ of gastric juice caused by anti-ulcerative agents has been shown to promote proliferation of pathogenic bacteria in the stomach. Aspiration of these bacteria is considered as one of the causes of VAP. Studies have shown that administration of anti-ulcerative agents that did not affect gastric acidity, such as sucralfate had a lower incidence of VAP, compared to proton pump inhibitors and $\mathrm{H} 2$ receptor blockers [16].

On the other hand, it is also important to improve the compliance of VAE preventive measures. Studies have shown that improving the compliance of preventive measures can shorten the time of MV and reduce the incidence of VAE. However, in China, the implementation status of VAE preventive measures, including VAP preventive measures, has not been reported, and the compliance with the above preventive measures may not be high. Therefore, this study aimed to investigate the implementation status of VAE preventive measures and influencing factors affecting their implementation status in the ICU of the 3A hospitals in Beijing-Tianjin-Hebei region of China.

"Corresponding Author: Prof. Okada Shinobu, Graduate school of nursing Chiba University, Japan, SO: 1-8-1, Inohana, Chuo-ku, Chiba-shi, Chiba, 260-0856, Japan; E-mail: sokada@faculty.chiba-u.jp

Citation: Longfei K, Shinobu O, Toshiko O (2022) Investigation and Analysis of the Current Situation of VAE Preventive Measures in ICU in Beijing-TianjinHebei Urban Agglomeration of China. Int J Nurs Clin Pract 9: 353. doi: https://doi. org/10.15344/2394-4978/2022/353

Copyright: (c) 2021 Longfei et al. This is an open-access article distributed under the terms of the Creative Commons Attribution License, which permits unrestricted use, distribution, and reproduction in any medium, provided the original author and source are credited. 
Citation: Longfei K, Shinobu O, Toshiko O (2022) Investigation and Analysis of the Current Situation of VAE Preventive Measures in ICU in Beijing-TianjinHebei Urban Agglomeration of China. Int J Nurs Clin Pract 9: 353. doi: https://doi.org/10.15344/2394-4978/2022/353

\section{Method}

\section{Survey recruitment procedure}

A web-based sampling method was used to select 40 ICUs from 47 tertiary university hospitals in the Beijing-Tianjin-Hebei region for the survey.

The researcher contacted the supervisors or senior nurses of these ICUs via WeChat (A free cell phone communication application) and explained the purpose of the study and the ethical considerations the researcher was committed to the study, such as confidentiality of hospital and respondent information. After obtaining permission, the researcher sent the two-dimensional code of the online questionnaire to them. The submission of the online questionnaire was considered consent.

The study was conducted with the approval of the Ethics Review Committee of the Chiba University Graduate School of Nursing (approval number: 31-54).

\section{Online questionnaire}

The questionnaire was divided into four parts: 1) Basic ICU information: number of nurses and physicians in each shift, number of beds and number of MV patients per day; 2) Implementation of VAE surveillance; 3) Implementation of preventive measures recommended in the VAP guidelines: head elevation to $30^{\circ}$ or more, oral care methods and frequency, hand hygiene, implementation of SAT and SBT, and use of sedatives. 4) Implementation of preventive measures for VAE other than VAP: fluid balance management, implementation of low tidal volume MV and tidal volume settings, and use of anti-ulcer drugs.

Participants were also asked to voluntarily answer the reason why each preventive measure was not implemented.

\section{Data analysis}

Descriptive statistics were calculated and relationships between answers were also analyzed. Student t-test was used for the comparison of continuous variables. Categorical data were compared using the chi-square test. All statistical analyses were performed with a statistical package for the social sciences software version 24.0 (SPSS, Chicago, IL, USA). For all analyses, p values less than 0.05 were considered significant.

\section{Results}

\section{General information of the subjected ICUs}

Thirty-two valid questionnaires were recovered from 40 distributed questionnaires, with a return rate of $80 \%$. The mean values for the number of beds, MV patients, nurses and physicians per shift in the ICU were $18.5 \pm 2.4,6.1 \pm 0.7,10.9 \pm 2.1$ and $4.3 \pm 4.4$, respectively.

Figure 1 shows the ratio of nurse per shift to beds and MV patients. Each nurse managed more than one bed in about $81 \%$ of ICUs and more than one MV patient in about $30 \%$ of ICUs; each physician managed more than 5 beds in about $65 \%$ of responding ICUs and managed more than one MV patient in half of ICUs.

\section{Implementation of VAE surveillance and monitoring items}

VAE surveillance was implemented in 29 of the 32 responding ICUs (90.6\%). Regarding the monitoring items in all ICUs, all items (VAP, pulmonary embolism, pneumothorax, pulmonary edema, atelectasis) were monitored in 14 ICUs (43.8\%). 9 ICUs (28.1\%) monitored some of them and remaining 6 ICUs (18.8\%) only monitored VAP.

3 ICU (9.4\%), in which VAE surveillance was not conducted, monitored only VAP, or pulmonary embolism, pneumothorax, and atelectasis, or pulmonary edema, pulmonary embolism, pneumothorax, and atelectasis.

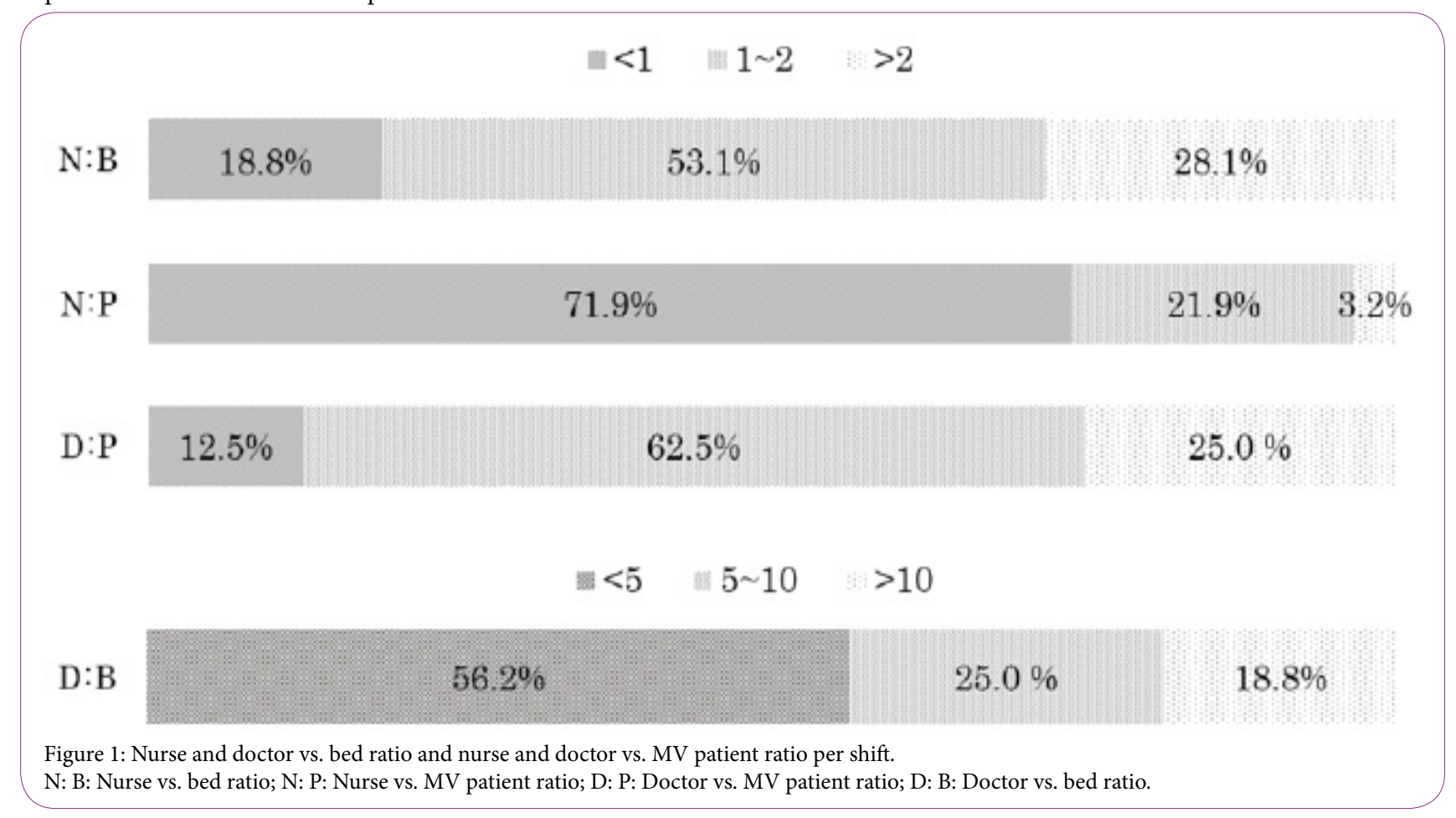


Citation: Longfei K, Shinobu O, Toshiko O (2022) Investigation and Analysis of the Current Situation of VAE Preventive Measures in ICU in Beijing-TianjinHebei Urban Agglomeration of China. Int J Nurs Clin Pract 9: 353. doi: https://doi.org/10.15344/2394-4978/2022/353

\section{Implementation of VAP preventive measures}

Table 1 shows the implementation of VAP prophylaxis. Bed head elevation at $30^{\circ}$ or greater was used in all ICUs. In 26 ICUs (81.2\%) both hand washing with soap and tap water and hand rubbing with alcohol sanitizer were used for hand hygiene. 15 ICUs (46.9\%) did not perform recommended amount of oral care (3 times a day or more). For oral care methods, brushing with toothbrush was adopted in only 8 ICUs (25.0\%). 25 ICUs (78.1\%) used the solution with bactericidal activity for oral care, and chlorhexidine gluconate was common. Although 26 ICUs (81.2\%) and 29 ICUs (90.7\%) implemented SAT and SBT, 13 ICUs (50\%) and 4 ICUs (13.8\%) implemented them daily, respectively.

\begin{tabular}{|c|c|c|}
\hline \multicolumn{2}{|c|}{ Implementation projects } & N (\%) \\
\hline \multicolumn{2}{|c|}{ VAP monitoring } & $28(87.5)$ \\
\hline \multicolumn{3}{|c|}{ Bed head elevation } \\
\hline \multirow[t]{2}{*}{ Setting } & $30^{\circ}$ & $18(56.2)$ \\
\hline & $>30^{\circ}$ & $14(43.8)$ \\
\hline \multicolumn{3}{|c|}{ Hand hygiene } \\
\hline \multirow[t]{2}{*}{ Method } & soap and running water & $6(18.8)$ \\
\hline & $\begin{array}{l}\text { soap and running water+ alcohol } \\
\text { hand sanitizer }\end{array}$ & $26(81.2)$ \\
\hline \multicolumn{3}{|l|}{ Oral care } \\
\hline \multirow[t]{3}{*}{ Frequency } & twice a day & $15(46.9)$ \\
\hline & 3 times a day & $8(25.0)$ \\
\hline & $\geq 4$ times a day & $9(28.2)$ \\
\hline \multirow[t]{2}{*}{ Method } & Brushing & $8(25.0)$ \\
\hline & non-brushing & $24(75.0)$ \\
\hline \multirow[t]{2}{*}{ Solution } & Bactericidal solution & $25(78.1)$ \\
\hline & saline & $7(21.9)$ \\
\hline \multicolumn{3}{|l|}{ SAT } \\
\hline \multirow[t]{2}{*}{ Frequency } & daily & $13(40.6)$ \\
\hline & irregular & $13(40.6)$ \\
\hline \multicolumn{3}{|l|}{ SBT } \\
\hline \multirow[t]{3}{*}{ Frequency } & daily & $4(12.5)$ \\
\hline & irregular & $10(31.2)$ \\
\hline & before extubation & $15(46.9)$ \\
\hline \multicolumn{2}{|c|}{ VAP care bundle } & $9(28.1)$ \\
\hline \multicolumn{3}{|c|}{$\begin{array}{l}\text { Table 1: Implementation status of VAP preventive measures. } \\
\text { VAP care bundle: Raise the bed head } 30^{\circ}+\text { use running water and soap } \\
\text { for hand hygiene+use } 2 \text { or more recommended oral care methods } \\
\text { (brushing for oral care/more than } 3 \text { times a day/use bactericidal } \\
\text { solution)+implement SAT and SBT. }\end{array}$} \\
\hline
\end{tabular}

Only 9 ICUs (28.1\%) implemented VAP care bundle when ICUs, which implemented bed head elevation $\left(>30^{\circ}\right)$, hand hygiene, oral care (implemented two or more items recommended in VAP guideline), SAT and SBT were considered to implement VAP care bundle. None of them did not perform SAT and SBT daily.

\section{Implementation of effective preventive measures for VAE other than VAP}

Table 2 shows the implementation of prophylactic measures for VAE other than VAP. For sedatives, 24 ICUs (75.0\%) used short-acting sedatives (propofol and dexmedetomidine) for a high usage, with 17 ICUs (53.1\%) mainly using the dexmedetomidine. Benzodiazepines continued to account for $50 \%$ or more of the sedatives in 10 ICUs $(31.2 \%)$. Maintaining negative fluid balance (OUT $>\mathrm{IN})$ was adopted in 8 ICUs (26.7\%). The number of ICUs that set tidal volume below 7 $\mathrm{mL} / \mathrm{kg}$ was only 3 (10.7\%). In most ICUs, proton pump inhibitors and $\mathrm{H} 2$ receptor blockers were dominantly used as anti-ulcer drugs, and the dominant usage of sucralfate was reported in only 6 ICUs (24.0\%).

\begin{tabular}{|c|c|}
\hline Monitoring items & $\mathrm{N}(\%)$ \\
\hline \multicolumn{2}{|l|}{ Sedative } \\
\hline Short-acting & $22(68.7)$ \\
\hline Dexmedetomidine & $17(53.1)$ \\
\hline Propofol & $5(15.6)$ \\
\hline \multicolumn{2}{|l|}{ Long-acting } \\
\hline Benzodiazepines & $10(31.3)$ \\
\hline \multicolumn{2}{|l|}{ Fluid balance control } \\
\hline Negative & $8(25.0)$ \\
\hline Non-negative & $22(68.8)$ \\
\hline \multicolumn{2}{|l|}{ LTVV } \\
\hline $0 \sim 7 \mathrm{~mL} / \mathrm{kg}$ & $3(9.4)$ \\
\hline $7-10 \mathrm{~mL} / \mathrm{kg}$ & $25(78.1)$ \\
\hline \multicolumn{2}{|l|}{ Anti-ulcer drugs } \\
\hline Dominant usage of $S$ & $6(18.7)$ \\
\hline Dominant usage of PPI and/or $\mathrm{H} 2$ & $19(59.4)$ \\
\hline \multicolumn{2}{|c|}{$\begin{array}{l}\text { Table 2: Implementation of preventive measures for VAE other than VAP } \\
\text { LTVV: Low tidal volume ventilation; } \\
\text { Short-acting: usage of Propofol and Dexmedetomidine }>50 \% \text {. } \\
\text { Long-acting: usage of Benzodiazepines }>50 \% \text {. } \\
\text { S: Sucralfate; PPI: proton pump inhibitors; H2: H2 receptor blockers. } \\
\text { Dominant usage of S: the usage of Sucralfate } \geq 1 / 3 \text {. } \\
\text { Dominant usage of PPI and/or H2: the usage of Sucralfate }<1 / 3 \text {. }\end{array}$} \\
\hline
\end{tabular}

\section{Implementation status of individual ICUs}

For the implementation of all 9 preventive measures (5 of the VAP care bundle shown in Table 1 and the primary use of shortacting sedatives, negative fluid balance, LTVV and the dominant use of sucralfate in Table 2), the mean of implemented items was $5.12 \pm 1.43 .20$ ICUs implemented 5 items or more ( 5 in 6 ICUs, 6 in 8 ICUs, 7 in 5 ICUs and 8 in 1 ICU), whereas the remaining 12 ICUs implemented only 4 or less (4 in 7 ICUs and 3 in 5 ICUs).

We also investigated the relationship between SAT, SBT and sedation implementation, since SBT in only possible when MV patients pass SAT and control of sedation must be controlled to make SAT successful. The results are shown in Table 3. Sedatives were classified as long-acting (midazolam) and short-acting ones (propofol or dexmedetomidine). Only one ICU implemented SAT and SBT daily. 11 of 13 ICUs that performed SAT daily performed SBT irregularly or before extubation. 2 ICUs conducted daily SBT without SAT. 5 of 26 ICUs performed SAT daily or irregularly and remained predominantly sedated with long-acting sedatives.

\section{Influence of facility characteristics on implementation status}

To clarify whether facility characteristics affect the implementation status of VAE preventative measures, the relationship between facility 


\begin{tabular}{|l|l|l|l|}
\hline \multicolumn{2}{|c|}{} & \multicolumn{2}{|c|}{ SAT } \\
\cline { 3 - 4 } \multicolumn{2}{|c|}{} & daily & irregular \\
\hline \multirow{3}{*}{ SBT } & daily & 1 & 2 \\
\cline { 2 - 4 } & irregular & 3 & 6 \\
\cline { 2 - 4 } & before extubation & 8 & 4 \\
\hline \multirow{3}{*}{ Sedative } & short-acting $^{1}$ & 10 & 11 \\
\cline { 2 - 4 } & long-acting $^{2}$ & 3 & 2 \\
\hline
\end{tabular}

Table 3: Implementation of SBT and sedative in ICUs implementing SAT.

${ }^{1}$ :usage of short-acting sedatives more than $50 \%$.

${ }^{2}$ :usage of long-acting sedatives more than $50 \%$.

characteristics and implementation status of VAE preventive measures were analyzed. The results are shown in Table 4 . ICUs with $\mathrm{N}$ vs. $\mathrm{P}$ ratio of less than 1 significantly implemented SAT compared with ICUs with larger $\mathrm{N}$ vs. P ratio ( $p=0.038$ ), and ICUs with $\mathrm{N}$ vs. B ratio of less than 2 preformed SAT significantly more often and regularly than ICUs with larger N vs. B ratio $(p=0.018)$. Moreover, ICUs with $\mathrm{N}$ vs. B ratio of less than 2 had significantly higher oral care frequency $(p=0.049)$ compared with ICUs with larger $\mathrm{N}$ vs. B ratio. ICUs with $\mathrm{N}$ vs. $\mathrm{P}$ ratio of less than 1 tended to use toothbrushes for oral care $(p=0.186)$ compared with an ICU with larger N vs. P ratio. ICUs with a D vs. B ratio of less than 5 significantly implemented SAT compared with ICUs with a larger D vs. B ratio $(p=0.047)$. ICUs with D vs. B ratio of less than 5 had significantly higher usage of dexmedetomidine compared with ICUs with larger D vs. B ratio $(p=0.004)$ (Table 4$)$.

No respondent answered the reason for not taking prophylaxis.

\section{Discussion}

\section{Characteristics (Outlines) of responded ICUs}

The investigated ICUs was affiliated with $3 \mathrm{~A}$ university hospitals, which are high level hospitals in China. The average number of beds, MV patients, nurses and physicians per shift are 18.5, 6.1, 10.9 and 4.3 respectively. According to the regulations on hospital classification in China, the number of beds in $3 \mathrm{~A}$ hospitals should be higher than those in lower-level hospitals. In terms of nurse bed ratio and nurse MV patient ratio, nearly half of ICU nurses need to take care of more than 2 patients per shift, and nearly one third of nurses need to take care of more than $1 \mathrm{MV}$ patient. This ratio is lower than the ratio of 1:1 per shift in the guidelines for ICU construction and management in China. This ratio is also lower than the 4:1 ratio of total nurses to beds in ICUs in the United States [17]. Clearly, even in ICU attached to 3A hospitals, there is a shortage of nursing staff.

\section{Implementation of VAE surveillance}

Of the 32 ICUs that responded, 29 ICUs monitored for VAE, and 14 of these monitored for all ventilator-associated complications from the questionnaire, including VAP, pulmonary embolism, pneumothorax, pulmonary edema, atelectasis, etc. The detection method of VAE is simple and required data are easily available from the electronic medical record. This is probably the main reason for monitoring VAE in most ICUs.

\section{Implementation status of VAP preventive measures}

Our findings suggested that implementation status of oral care, SAT and SBT were not enough in Chinese ICU.
For oral care, the percentage of ICUs that did not perform oral care at the recommended frequency (three or more times a day) was $46.9 \%$, and only eight ICUs (25\%) used a toothbrush in oral care of MV patients (Table 1). The oral status of patients with endotracheal intubation is complex. This makes it difficult and time-consuming to perform oral care and brush the oral cavity with toothbrush in MV patients. It seems difficult to provide adequate oral care and to have an opportunity for improving oral care skill for patients with endotracheal intubation when there is a shortage of nursing staff in ICU. The frequency of oral care in the ICUs with fewer nursing staff is significantly lower, which indicates this possibility (Table 4 ).

Due to the low implementation rate of daily SAT and SBT, most physicians continue to use traditional weaning methods based on clinical judgment or experience because of a lack of systematic knowledge of MV weaning [20]. Physicians' empirical treatment may be due to the fact that VAP guidelines have not been fully popularized in China.

SAT and SBT are recommended to be implemented in pairs. However, the vast majority of ICUs that perform daily SAT did not perform SBT regularly or before extubation (Table 3). This indicates that the prevalence of paired SAT and SBT prophylaxis is very low, or in other words, that daily paired SAT and SBT are not standardized.

The relative shortage of physicians will directly affect the implementation of SAT. Nurses caring for MV patients also played a role in the implementation of SAT and SBT, especially SAT. Nurses' advice to physicians on MV patients likely to pass SAT is also important in the implementation of daily SAT. Research have shown that nurse-led sedation can reduce the duration of $\mathrm{MV}$, and the length of stay in the ICU. For nurse-led sedation, it is necessary to observe MV patients frequently and to assess appropriate sedative levels. If nurses do not have enough time to observe MV patients carefully due to understaffing, they may prefer deeper sedation, which will delay withdrawal. In fact, meta-analysis has shown that the nurse-patient ratio is an important factor affecting nurses' workload and disturbing sedation, and understaffing had a tendency to be under sedated and over sedated [19]. Understaffing will prevent nurses from finding enough time for the assessment of SAT. In addition, education on SAT for ICU nurses may be inadequate.

\section{Implementation status of VAE preventive measure}

The implementation rate of effective VAE other than VAP prophylaxis were generally lower than that of VAP prophylaxis.

For the choice of sedatives, recent studies have shown that benzodiazepines are more likely to lead to adverse clinical outcomes [18], whereas propofol and dexmedetomidine can shorten the duration of mechanical ventilation and reduce the incidence of VAE [11]. However, ICUs, in which dexmedetomidine was used for more than $50 \%$ (Table 2), was 17 of 32, and most were in ICU with understaffing of physicians (D vs. B ratio less than 5 , Table 4). Compared with propofol and midazolam, dexmedetomidine is relatively newly launched and its production began in 2018 in China. Therefore, the use of dexmedetomidine still requires learning and clinical practice, and physicians in ICU with low Dvs. B ratio may have more time to learn and practice the use of dexmedetomidine. Higher drug price may also influence the choice of sedatives. In addition, 5 out of 10 ICUs implementing SAT used primarily benzodiazepines for sedation (Table 3). Successful SAT and early exit from MV should 
Citation: Longfei K, Shinobu O, Toshiko O (2022) Investigation and Analysis of the Current Situation of VAE Preventive Measures in ICU in Beijing-TianjinHebei Urban Agglomeration of China. Int J Nurs Clin Pract 9: 353. doi: https://doi.org/10.15344/2394-4978/2022/353

\begin{tabular}{|c|c|c|c|c|c|c|c|c|c|c|c|c|}
\hline & \multicolumn{3}{|c|}{$\mathrm{N}$ vs. B ratio } & \multicolumn{3}{|c|}{$\mathrm{N}$ vs. $\mathrm{P}$ ratio } & \multicolumn{3}{|c|}{ D vs. B ratio } & \multicolumn{3}{|c|}{ D vs. $P$ ratio } \\
\hline & $<2$ & $>2$ & $P$ & $<1$ & $>1$ & $P$ & $<5$ & $>5$ & $P$ & $<2$ & $>2$ & $P$ \\
\hline \multicolumn{13}{|l|}{ Oral care } \\
\hline \multicolumn{13}{|l|}{ Method } \\
\hline Brushing & 4 & 4 & 0.414 & 5 & 3 & 0.186 & 5 & 3 & 0.539 & 4 & 4 & 0.838 \\
\hline Not brushing & 13 & 11 & & 17 & 7 & & 12 & 12 & & 13 & 11 & \\
\hline \multicolumn{13}{|l|}{ Frequency } \\
\hline$<4$ times a day & 10 & 13 & $0.049^{*}$ & 15 & 8 & 0.874 & 11 & 12 & 0.337 & 11 & 12 & 0.337 \\
\hline$>4$ times a day & 7 & 2 & & 7 & 2 & & 6 & 3 & & 6 & 3 & \\
\hline \multicolumn{13}{|l|}{ SAT } \\
\hline \multicolumn{13}{|l|}{ Implementation } \\
\hline YES & 12 & 14 & 0.365 & 20 & 6 & $0.038^{*}$ & 16 & 10 & $0.047^{*}$ & 15 & 11 & 0.281 \\
\hline NO & 4 & 2 & & 2 & 4 & & 1 & 5 & & 2 & 4 & \\
\hline \multicolumn{13}{|l|}{ Frequency } \\
\hline Daily & 9 & 4 & $0.018^{*}$ & 8 & 5 & 0.690 & 7 & 6 & 0.420 & 6 & 7 & 0.234 \\
\hline Other & 3 & 10 & & 10 & 3 & & 9 & 4 & & 9 & 4 & \\
\hline \multicolumn{13}{|l|}{ SBT } \\
\hline \multicolumn{13}{|l|}{ Implementation } \\
\hline YES & 15 & 14 & 0.544 & 19 & 10 & 0.935 & 14 & 15 & 0.087 & 16 & 13 & 0.471 \\
\hline NO & 2 & 1 & & 3 & 0 & & 3 & 0 & & 1 & 2 & \\
\hline \multicolumn{13}{|l|}{ Frequency } \\
\hline Daily & 2 & 2 & 0.945 & 3 & 1 & 0.849 & 2 & 2 & 0.941 & 3 & 1 & 0.390 \\
\hline Other & 13 & 12 & & 16 & 9 & & 12 & 13 & & 13 & 12 & \\
\hline \multicolumn{13}{|l|}{ Sedative } \\
\hline \multicolumn{13}{|l|}{ Usage } \\
\hline $\mathrm{B}<50 \%$ & 14 & 7 & 0.582 & 15 & 6 & 0.638 & 15 & 6 & $0.004^{*}$ & 13 & 8 & 0.169 \\
\hline $\mathrm{B}>50 \%$ & 7 & 4 & & 8 & 3 & & 2 & 9 & & 4 & 7 & \\
\hline \multicolumn{13}{|c|}{ Fluid balance control } \\
\hline \multicolumn{13}{|c|}{ Implementation } \\
\hline YES & 15 & 15 & 0.144 & 20 & 10 & 0.555 & 16 & 14 & 0.927 & 16 & 14 & 0.927 \\
\hline NO & 2 & 0 & & 2 & 0 & & 1 & 1 & & 1 & 1 & \\
\hline \multicolumn{13}{|l|}{ Indicator } \\
\hline Negative & 5 & 3 & 0.825 & 7 & 1 & 0.589 & 7 & 1 & $0.024^{\star}$ & 5 & 3 & 0.544 \\
\hline Non-negative & 10 & 12 & & 13 & 9 & & 9 & 13 & & 11 & 11 & \\
\hline LTVV & & & & & & & & & & & & \\
\hline Implementatiol & & & & & & & & & & & & \\
\hline YES & 14 & 14 & 0.285 & 19 & 9 & 0.387 & 15 & 13 & 0.893 & 15 & 13 & 0.893 \\
\hline $\mathrm{NO}$ & 3 & 1 & & 3 & 1 & & 2 & 2 & & 2 & 2 & \\
\hline Setting & & & & & & & & & & & & \\
\hline$\leq 7 \mathrm{~mL} / \mathrm{kg}$ & 1 & 2 & 0.630 & 2 & 1 & 0.122 & 3 & 0 & 0.088 & 1 & 2 & 0.457 \\
\hline $7 \sim 10 \mathrm{~mL} / \mathrm{kg}$ & 13 & 12 & & 17 & 8 & & 12 & 13 & & 14 & 11 & \\
\hline Anti-ulcer druq & & & & & & & & & & & & \\
\hline Implementatior & & & & & & & & & & & & \\
\hline YES & 13 & 10 & 0.411 & 16 & 7 & 0.595 & 14 & 9 & 0.160 & 12 & 11 & 0.863 \\
\hline NO & 4 & 5 & & 6 & 3 & & 3 & 6 & & 5 & 4 & \\
\hline Usage & & & & & & & & & & & & \\
\hline$S>1 / 3$ & 5 & 1 & 0.123 & 4 & 2 & 0.858 & 5 & 1 & 0.190 & 5 & 1 & 0.076 \\
\hline $\mathrm{S}<1 / 3$ & 8 & 9 & & 12 & 5 & & 9 & 8 & & 7 & 10 & \\
\hline $\begin{array}{l}\mathrm{N} \text { vs. B ratio: } \mathrm{Nu} \\
\mathrm{D} \text { vs. B ratio: } \mathrm{Do} \\
\text { B: Benzodiazenp } \\
\text { Apply the chi-sq } \\
{ }^{\star} P<0.05\end{array}$ & $\begin{array}{l}\text { s. be } \\
\text { vs. b } \\
\text { LTV }\end{array}$ & $\begin{array}{l}\text { o; N } \\
\text { tio; I } \\
\text { ow ti }\end{array}$ & $\begin{array}{l}\text { ratio: } \mathrm{N} \\
\text { P ratio: } \mathrm{D} \\
\text { olume ve } \\
\text { relation }\end{array}$ & rse v & $\begin{array}{l}J \text { pati } \\
\text { MV pa } \\
\text { GRV:C } \\
\text { en eac }\end{array}$ & $\begin{array}{l}\text { ratio. } \\
\text { t ratio. } \\
\text { ric remai } \\
\text { ceventive }\end{array}$ & $\begin{array}{l}\text { ing } \mathrm{v} \\
\text { measu }\end{array}$ & $\begin{array}{l}\text { ne; S: } \\
\text { and } N\end{array}$ & $\begin{array}{l}\text { calfate; D } \\
3 \text { and } N\end{array}$ & $\begin{array}{l}\text { dexm } \\
\text { s. P ra }\end{array}$ & tomi & \\
\hline
\end{tabular}


Citation: Longfei K, Shinobu O, Toshiko O (2022) Investigation and Analysis of the Current Situation of VAE Preventive Measures in ICU in Beijing-TianjinHebei Urban Agglomeration of China. Int J Nurs Clin Pract 9: 353. doi: https://doi.org/10.15344/2394-4978/2022/353

Page 6 of 6

be considered to avoid deep sedation. This may be related to the high heterogeneous population of critically ill patients. Their disease type, pathophysiological mechanism, disease progression and severity of ICU patients under MV require deep sedation in some cases to meet specific therapeutic purposes.

Only 8 (25\%) of 32 ICUs adopted negative fluid balance as a criterion for fluid balance management in MV patients. Depending on the patient's conditions such as hemorrhagic shock, diabetic ketoacidosis, heat stroke, etc. at the time of ICU admission, fluid resuscitation is necessary. When the patient is stable, the physician may prefer to maintain the patient's intake and output to prevent the adverse effects of positive or negative fluid balance.

The principle of the effectiveness of LTVV is that small tidal volumes are unlikely to develop over-expansion of the alveoli, which is one of the main causes of ventilator-associated lung injury. However LVTT was conducted in only 3 ICUs. In most ICUs the ventilator tidal volumes were set at $7 \sim 10 \mathrm{~mL} / \mathrm{kg}$. In general, tidal volumes are calculated based on patent's body weight, which may be inaccurate when measuring the patient's body weight because patients is often lying down when arriving at ICU. In addition, tidal volumes are often set too large at the beginning on MV. The prevention of atelectasis in sedated patients and treatment of ARDS may be the main reasons for large tidal volumes. When choosing a mechanical ventilation mode, the physicians prefer to control of airway pressure rather than tidal volume. In patients with good lung compliance, physicians generally choose normal tidal volume.

Proton pump inhibitors or $\mathrm{H}-2$ blockers was primarily used in nearly $80 \%$ of responded ICUs for the prevention of stress ulcers. They work by increasing the $\mathrm{pH}$ of gastric juice by reducing the secretion of gastric acid. However, elevated $\mathrm{pH}$ promotes bacterial colonization in the stomach and increases the risk of VAP. Therefore, sucralfate which acts by increasing mucus secretion and hence does not increase the gastric $\mathrm{pH}$, is recommended for VAP prevention. Although some ICUs used sucralfate, the dominant use of sucralfate remains in minority. This may be due to less effectiveness of sucralfate in reducing gastrointestinal bleeding.

\section{Conclusions}

Through the questionnaire survey on the implementation of VAE preventive measures, it is necessary to increase the compliance of daily SAT and SBT and frequency of oral care and toothbrush scrubbing. In addition, it is also necessary to discuss medicines for sedation, body fluid management, ventilator parameters and anti-ulcer drugs for the prevention of VAE in MV patients.

\section{Limitation}

Our survey targets are limited in number and region and may only a fraction of implementation status of the entire Chinese implementation. Further, the reasons for the difficulty or failure to implement the preventive measures were not obtained.

\section{Competing Interests}

The authors declare that they have no competing interests.

\section{Acknowledgments}

Our study was supported by head nurse Liping Wu of ICU of the first hospital of Hebei Medical University. We would like to thank head nurse Liping $\mathrm{Wu}$ for contacting each ICU responded in this study.

\section{References}

1. Heyland DK, Cook DJ, Griffith L, Keenan SP, Brun-Buisson C, et al. (1999) The attributable morbidity and mortality of ventilator-associated pneumonia in the critically ill patient. The Canadian Critical Trials Group. Am J Respir Crit Care Med 159: 1249-1256.

2. Chevret $\mathrm{S}$, Hemmer $\mathrm{M}$, Carlet J, Langer M (1993) Incidence and risk factors of pneumonia acquired in intensive care units. Results from a multicenter prospective study on 996 patients. European Cooperative Group on Nosocomial Pneumonia. Intensive Care Med 19: 256-264.

3. Haley RW, Hooton TM, Culver DH, Stanley RC, Emori TG, et al. (1981) Nosocomial infections in US hospitals, 1975-1976: estimated frequency by selected characteristics of patients. Am J Med 70: 947-959.

4. Celis R, Torres A, Gatell JM, Almela M, Rodríguez-Roisin R, et al. (1988) Nosocomial pneumonia: a multivariate analysis of risk and prognosis. Chest 93: 318-324.

5. Chastre J, Fagon JY (2002) Ventilator-associated pneumonia. Am J Respir Crit Care Med 165: 867-903.

6. Klompas M, Anderson D, Trick W, Babcock H, Kerlin MP, et al. (2015) The preventability of ventilator-associated events. The CDC prevention epicenters wake up and breathe collaborative. Am J Respir Crit Care Med 191: 292-301.

7. Stevens JP, Silva G, Gillis J, Novack V, Talmor D, et al. (2014) Automated surveillance for ventilator-associated events. Chest 146: 1612-1618.

8. Zhu S, Cai L, Ma C, Zeng H, Guo H, et al. (2015) The Clinical Impact of Ventilator-Associated Events: A Prospective Multi-Center Surveillance Study. Infect Control Hosp Epidemiol 36: 1388-1395.

9. Klompas M, Khan Y, Kleinman K, Evans RS, Lloyd JF, et al. (2011) Multicenter evaluation of a novel surveillance paradigm for complications of mechanical ventilation. PLoS One 6: e18062.

10. Boyer AF, Schoenberg N, Babcock H, McMullen KM, Micek ST, et al. (2015) A prospective evaluation of ventilator-associated conditions and infectionrelated ventilator-associated conditions. Chest 147: 68-81.

11. Lewis SC, Li L, Murphy MV, Klompas M, CDC Prevention Epicenters, et al. (2014) Risk factors for ventilator-associated events: a case-control multivariable analysis. Crit Care Med 42: 1839-1848.

12. Klompas M, Li L, Szumita P, Kleinman K, Murphy MV et al. (2016) Associations between different sedatives and ventilator-associated events, length of stay, and mortality in patients who were mechanically ventilated. Chest 149: 1373-1379.

13. Li G, Malinchoc M, Cartin-Ceba R, Venkata CV, Kor DJ, et al. (2011) Eight-year trend of acute respiratory distress syndrome: a population-based study in Olmsted County, Minnesota. Am J Respir Crit Care Med 183: 59-66.

14. Neto AS, Cardoso SO, Manetta JA, Pereira VGM, Espósito DC, et al. (2012) Association between use of lung-protective ventilation with lower tidal volumes and clinical outcomes among patients without acute respiratory distress syndrome: a meta-analysis. JAMA 308: 1651-1659.

15. Neto AS, Simonis FD, Barbas CS, Biehl M, Determann RM, et al. (2015) Lung-protective ventilation with low tidal volumes and the occurrence of pulmonary complications in patients without acute respiratory distress syndrome: a systematic review and individual patient data analysis. Crit Care Med 43: 2155-2163.

16. Grindlinger GA, Cairo SB, Duperre CB (2016) Pneumonia prevention in intubated patients given sucralfate versus proton-pump inhibitors and/or histamine II receptor blockers. J Surg Res 206: 398-404.

17. 陈芳. 美国 ICU (2018) 护理管理概况. 护士进修杂志 33: 952-954.

18. Fraser GL, Devlin JW, Worby CP, Alhazzani W, Barr J, et al. (2013) Benzodiazepine versus nonbenzodiazepine-based sedation for mechanically ventilated, critically ill adults: a systematic review and metaanalysis of randomized trials. Crit Care Med 41: 30-38. 